\title{
Detección de Listeria spp. y Listeria monocytogenes en muestras de leche cruda y quesos artesanales respectivamente, mediante PCR en Tiempo Real
}

\section{Detection of Listeria spp. and Listeria monocytogenes in samples of raw milk and artisanal cheeses respectively, using Real Time PCR}

\section{Detecção de Listeria spp. e Listeria monocytogenes em amostras de leite cru e queijos artesanais, respectivamente, através de PCR em Tempo Real}

\author{
Viviana Pamela Chiluisa-Utreras ${ }^{1}$, María Alexandra Cabrera-Rodríguez ${ }^{2}$ y Priscila Karina Valladares-Torres ${ }^{3}$
}

Forma de citar: V.P. Chiluisa-Utreras, M.A. Cabrera-Rodríguez y P.K. Valladares-Torres, "Detección de Listeria spp. y Listeria monocytogenes en muestras de leche cruda y quesos artesanales respectivamente, mediante PCR en Tiempo Real”, Respuestas, vol. 22, no. 2, pp. 67-75, 2017.

Recibido:

Enero 12 de 2017

Aceptado:

Mayo 28 de 2017
'Magíster en Biología de la Conservación vchiluisa@ups.edu.ec Orcid: 0000-0001-8647-1791

Grupo de Investigación BIOARN

Universidad Politécnica Salesiana

Quito, Ecuador

${ }^{2}$ Ingeniera en Biotecnología de los RRNN

alex_avc1928@hotmail.com Orcid: 0000-0002-3509-5447

Universidad Politécnica

Salesiana

Quito, Ecuador

${ }^{3}$ Ingeniera en Biotecnología de los RRNN

p_ris7@hotmail.com Orcid: 0000-0003-1188-5601

Universidad Politécnica

Salesiana

Quito, Ecuador

\section{Resumen}

Antecedentes. En Ecuador, los estudios sobre las bacterias del género Listeria son escasos en quesos artesanales y en leche cruda prácticamente inexistentes. La producción de leche es una de las principales actividades ganaderas en la provincia de Pichincha y se hace indispensable el estudio de estos productos. Siendo todos los cantones que conforman Pichincha, productores de leche, se muestrea al azar tres de ellos, Cayambe, Quito y Pedro Moncayo. Objetivo. Determinar Listeria spp. y Listeria monocytogenes en muestras de leche cruda y quesos artesanales respectivamente, mediante PCR en Tiempo Real. Métodos. La aplicación de la técnica qPCR en la detección de microorganismos y sobre todo de bacterias en alimentos, se basa en cuatro aspectos fundamentales: su sensibilidad, especificidad, rapidez y capacidad de procesamiento de gran flujo de muestras. Es posible detectar pequeñas cantidades de microorganismos patógenos, como es el caso de Listeria spp. en leche cruda, previa extracción y cuantificación de ADN total. Resultados. En este estudio en leche cruda, se determinó 1 positivo de un total de 60 muestras, que representa el 1.6\% de Listeria spp. y 16 muestras positivas de 45, que representa el $35.6 \%$ de Listeriamonocytogenes en quesos artesanales de tres haciendas de la provincia de Pichincha. Conclusiones. Los resultados, de acuerdo a los análisis estadísticos realizados con la prueba de Kruskal - Wallis, demuestran que en Pichincha se encuentra presente la bacteria en leche cruda, pero en cantidades no representativas, mientras que para Listeria monocytogenes existe significancia estadística en las muestras de quesos artesanales.

Palabras clave: Ecuador, Leche Cruda, Listeria, PCR en Tiempo Real, quesos artesanales.

\begin{abstract}
Background. In Ecuador, studies about bacteria genre Listeria in artisanal cheeses are scarce, and in raw milk, practically nonexistent. Milk production is one of the main livestock activities in the province of Pichincha and it is essential to study these products. Since all the cantons that make up Pichincha are milk producers, three of them, Cayambe, Quito and Pedro Moncayo were randomly sampled. Objective. To determine Listeria spp. and Listeria monocytogenes in samples of raw milk and artisanal cheeses, respectively,
\end{abstract}


No. 2 using Real Time PCR. Methods. The application of the qPCR technique in the detection of microorganisms and especially of bacteria in food, is based on four fundamental aspects: its sensitivity, specificity, speed and processing capacity of large sample flow. It is possible to detect small amounts of pathogenic microorganisms, such as Listeria spp in raw milk, after extraction and quantification of total DNA. Results. In this study in raw milk, one positive was determined from a total of 60 samples, representing $1.6 \%$ of Listeria spp. and 16 positive samples of 45 , representing $35.6 \%$ of Listeria monocytogenes in artisanal cheeses from three farms in the province of Pichincha. Conclusions. The results, according to the statistical analyzes carried out with the Kruskal - Wallis test, show that in Pichincha the bacterium is present in raw milk, but in non - representative quantities, whereas for Listeria monocytogenes there is statistical significance in the cheeses samples.

Keywords: Ecuador, Raw Milk, Listeria, Real Time PCR, Artisanal cheeses.

\section{Resumo}

Antecedentes. No Equador, estudos sobre a bactéria do gênero Listeria são escassos em queijos artesanais e em leite cru praticamente inexistentes. A produção de leite é uma das principais atividades pecuárias na província de Pichincha e é essencial estudar esses produtos. Como todos os cantões que compõem Pichincha, produtores de leite, são amostrados aleatoriamente três deles, Cayambe, Quito e Pedro Moncayo. Objetivo. Determine Listeria spp. e Listeria monocytogenes em amostras de leite cru e queijos artesanais, respectivamente, utilizando PCR em tempo real. Métodos. A aplicação da técnica qPCR na detecção de microorganismos e especialmente de bactérias nos alimentos, baseia-se em quatro aspectos fundamentais: sua sensibilidade, especificidade, velocidade e capacidade de processamento de grande fluxo de amostra. É possível detectar pequenas quantidades de microorganismos patogênicos, como Listeria spp. em leite cru, extração prévia e quantificação do DNA total. Resultados. Neste estudo, no leite cru, 1 positivo foi determinado a partir de um total de 60 amostras, representando 1,6\% da Listeria spp. e 16 amostras positivas de 45 , representando $35,6 \%$ de Listeria monocytogenes em queijos artesanais de três fazendas na província de Pichincha. Conclusões. Os resultados, de acordo com as análises estatísticas realizadas com o teste de Kruskal - Wallis, mostram que, em Pichincha, a bactéria está presente no leite cru, mas em quantidades não representativas, enquanto que para Listeria monocytogenes há significância estatística nas amostras de queijo ofícios

Palavras-chave: Equador, leite cru, Listeria, PCR em tempo real, queijos artesanais.

\section{Introducción}

La industria lechera en la provincia de Pichincha constituye una fuente principal para la economía y contribuye a la soberanía del país [1]. Sin embargo, la falta de implementación de Buenas Prácticas de Manufactura y la falta de procedimientos rápidos y efectivos para la identificación de bacterias patógenas, repercute con problemas de salud en el consumidor, especialmente en los recién nacidos, mujeres embarazadas $\mathrm{y}$ ancianos [2], [3].

Las técnicas de identificación basadas en el cultivo y las características fenotípicas de las bacterias, requieren de trabajos minuciosos y muy laboriosos, por lo que no resulta viable cuando se analizan alimentos perecederos como son la leche, quesos artesanales y 
demás productos lácteos [4]. La aplicación de métodos como la Reacción en Cadena de la Polimerasa (PCR) es de gran ayuda, debido a que permite obtener un control más eficiente del proceso de producción y tomar decisiones a corto plazo, pues con este método de identificación se puede detectar la presencia de microorganismos aun cuando se encuentren pequeñas cantidades de los mismos [5].

El género Listeria se encuentra en el ambiente y puede contaminar varios alimentos sea a partir de su origen, o por manipuladores de los mismos, algunos de estos alimentos susceptibles de contaminación son la leche cruda y los quesos que en la provincia de Pichincha se producen de forma industrial y artesanal [6], [5]. La presencia de este microorganismo en el hombre, produce una infección bacteriana que puede infectar a varias células del organismo, pero principalmente a las del tracto gastrointestinal, pues coloniza al intestino y puede cruzar la barrera intestinal, propagándose a las barreras hematoencefálicas y en caso de embarazo la barrera materno-fetal. Esta infección no es muy común y afecta, sobre todo, a personas inmunodeprimidas [7].

Los estudios sobre Listeria spp. y Listeria monocytogenes tanto en Pichincha como en el Ecuador son escasos en leche cruda y en quesos casi inexistentes, por lo que esta investigación genera un acercamiento a conocer si en el país existe riesgo con este microorganismo, pues al ser patógeno, ocasiona peligro para el consumir [5].

\section{Materiales y métodos}

\subsection{Localización y tamaño de la muestra}

El presente estudio se llevó a cabo en los Laboratorios de Ciencias de la Vida de la Universidad Politécnica Salesiana en Quito, con 45 muestras de queso artesanal y 60 muestras de leche de vaca de raza Holstein que fueron escogidas aleatoriamente en tres haciendas productoras de Chillogallo, Cayambe y Tabacundo de la provincia de Pichincha.

\subsection{Extracción de ácidos nucleicos}

Para la extracción de ácidos nucleicos se utilizó el protocolo de BIOTECON Diagnostics que detalla la utilización de un tubo colector de $1.5 \mathrm{~mL}$ en el que se colocó $1 \mathrm{~mL}$ de muestra de leche o $1 \mathrm{~mL}$ de caldo de enriquecimiento para Listeria en donde se incubó el queso, el cual se trató con buffer de lisis, posteriormente con solución de lisozima, binding buffer y proteinasa $\mathrm{K}$.

Se añadió etanol al 95\% para precipitar el ADN, se retiró el sobrenadante y se colocó en un tubo de columna, en el que se añadió Wash Buffer al tubo filtro, repitiendo este proceso dos veces. Se adicionó en el tubo filtro Elution Buffer que ayudó a filtrar el ADN, para tener aproximadamente $50 \mu \mathrm{L}$ de muestra para el posterior análisis.

\subsection{Cuantificación de ADN}

En el equipo Qubit 2.0 Fluorometer® se realizó la cuantificación de ADN con el kit específico en el que se leyó cada muestra determinando la cuantificación de las mismas en $\mathrm{ng} / \mathrm{mL}$ y la configuración del equipo según el volumen de muestra tomado.

\subsection{Téenica de PCR en Tiempo Real}

Para la preparación de las muestras a amplificar se utilizó el protocolo foodproof $\mathbb{}$ Listeria Genus Detection Kit y foodproof $\mathbb{}$ Listeria monocytogenes Detection Kit, que detalla la preparación de la Master Mix con primers preparados, una sonda de hibridación específica para ADN de Listeria y un control interno determinado en cada prueba para evitar resultados inválidos. Se utilizaron capilares de $20 \mu \mathrm{L}$, en los cuales se colocaron $15 \mu \mathrm{L}$ de Master Mix y $5 \mu \mathrm{L}$ de la muestra de ADN. Se transfirieron los capilares al 


\subsection{Análisis estadístico}

Los métodos estadísticos utilizados para este estudio fueron Shapiro-Wilks y KruskallWallis, realizados por medio de herramientas de análisis de datos a través del programa estadístico INFOSTAT.

\section{Resultados y análisis}

\subsection{Extracción de ADN total}

La obtención de los ácidos nucleicos por medio de un kit de extracción comercial específico para bacterias ha resultado ser más efectiva ya que se puede obtener un ADN de alta calidad con poca probabilidad de degradación. Es necesario realizar una extracción de ADN libre de sustancias inhibitorias como proteínas, que alteran los resultados de la amplificación por PCR en Tiempo Real. Todas las muestras presentaron $\mathrm{ADN}$, lo que se corroboró con la cuantificación para su posterior amplificación [8]-[10].

\subsection{Cuantificación de ácidos nucleicos}

En este estudio se pudo determinar que mediantela técnicadeQubit2.0Fluorometer ${ }^{\circledR}$, las muestras evaluadas presentaron ADN total. En la tabla I, se aprecia el promedio de ADN total extraído por hacienda, por muestra y según las repeticiones.

Tabla I. Promedios de concentraciones de ADN total en ng/ml*

\begin{tabular}{|c|c|c|c|}
\hline HACIENDAS & MUESTRAS & REPETICIONES & PROMEDIOS (ng/mL) \\
\hline Hacienda A & Leche cruda & 20 & $3,43 \mathrm{E}+03$ \\
\hline Hacienda B & Leche cruda & 20 & $2,84 \mathrm{E}+03$ \\
\hline Hacienda C & Leche cruda & 15 & $2,25 \mathrm{E}+03$ \\
\hline Hacienda A & Queso artesanal & 15 & $4,06 \mathrm{E}+03$ \\
\hline Hacienda B & Queso artesanal & 15 & $3,23 \mathrm{E}+03$ \\
\hline Hacienda C & Queso artesanal & *No se pueden reportar los nombres de las Haciendas \\
\hline
\end{tabular}

La cuantificación se llevó a cabo con el fin de determinar que la extracción de ADN sea exitosa para realizar la amplificación posterior, sin embargo, no determina la presencia de Listeria, pues este patógeno puede presentarse en productos lácteos inclusive a bajas concentraciones de ADN [11].

\subsection{Detección de Listeria por PCR en Tiempo Real}

En la figura 1, se puede visualizar que en el eje de las ordenadas se expresa la fluorescencia que detecta el termociclador y en el eje de las abscisas se expresa el número de ciclos de la PCR en Tiempo Real. En el caso de leche cruda, se aprecia que las curvas tienen tendencia negativa y no presentan forma específica. El control positivo cuyo crossing point (CP), se empezó a dar en el ciclo 30 , muestra una curva diferente a las de las demás, en vista que se trata de un caso positivo.

Los datos obtenidos se configuraron en una matriz binaria de 0 y 1 para determninar la ausencia o presencia de Listeria, los mismos fueron analizados mediante el programa estadístico INFOSTAT con la prueba de Shapiro-Wilks que determinó que los datos no eran normales [12], [13], facilitando la aplicación de la prueba no paramétrica de Kruskall Wallis que arrojó para el caso de leche cruda un $\mathrm{H}$ igual a 0.10 


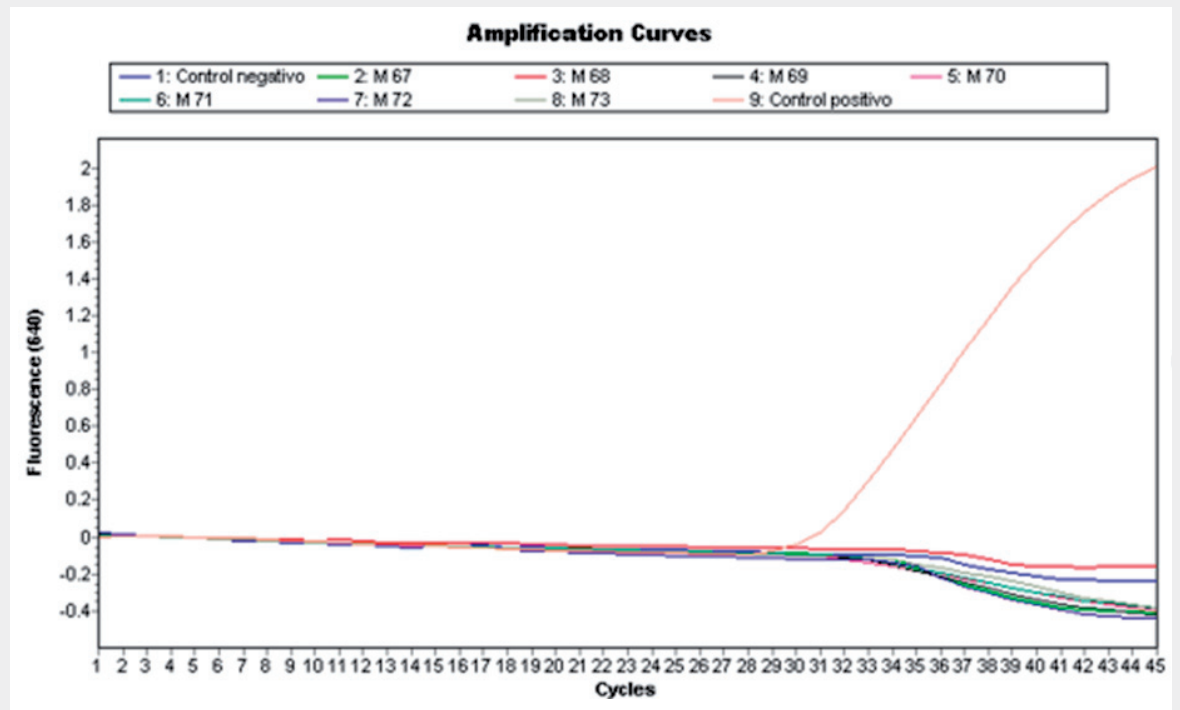

No. 2

Julio - Dic. 2017

ISSN 0122-820X

E-ISSN 2422-5053

Figura 1. Curva de Amplificación de Listeria spp.en leche cruda; canal de fluorescencia 640.

y p igual a 0.3679 , valores que presentan una probabilidad asociada mayor al alfa escogido 0.05 , aceptando así la hipotesis nula que menciona que, las muestras de leche cruda de tres haciendas de la provincia de Pichincha no presentan Listeria spp. determinadas por PCR en Tiempo Real. Esto se debe a que las medianas son estadísticamente similares [12].

Para el caso de quesos artesanales, en la prueba estadística no paramétrica de Kruskall Wallis se obtuvo un H igual a 4.83 y $\mathrm{p}$ igual a 0.0299 , valores que presentan una probabilidad asociada menor al 95\% de confianza, aceptando así la hipotesis alternativa que menciona que en las muestras de quesos artesanales de tres haciendas de la provincia de Pichincha, al menos una presenta Listeria monocytogenes determinadas por PCR en Tiempo Real.

En la figura 2 se muestran las curvas de amplificación y se determina que la Hacienda B es aquella que presenta mayor desviación microbiológica de Listeria monocytogenes en las muestras de quesos.

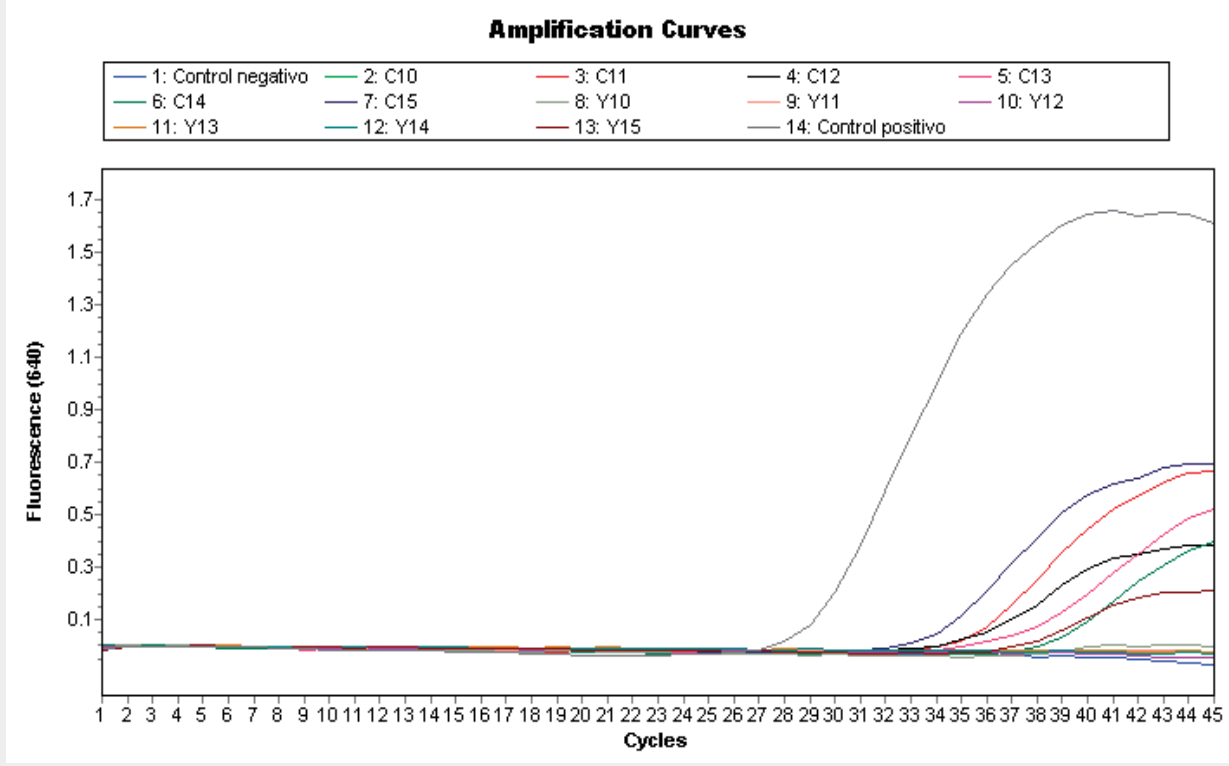

Figura 2. Curva de amplificación de Listeria monocytogenes en quesos artesanales; canal de detección 640. 
La ausencia de Listeria spp. en leche cruda se debe a varios factores como composición del suelo, tipo de alimentación del ganado, condiciones ambientales, higiene del ordeño y comportamiento bacteriano.

Las fuentes de Listeria spp. en leche cruda provienen de contaminación fecal y del medio ambiente durante el ordeño, almacenamiento y transporte, los animales infectados o enfermos y la mala calidad del ensilaje [14]. Los suelos son un factor determinante en la calidad de la leche, sobre todo en la presencia de bacterias patógenas que escalan al pasto que consume el ganado. Entre la biota del suelo se encuentran algunas especies de Listeria, pero por la competencia existente entre la misma y otras especies bacterianas, es escasa su presencia en el forraje [15], sumado a esto, los nutrientes que un animal requiere en cantidades relativamente grandes como fósforo, potasio, calcio, magnesio, que obtiene de los forrajes cultivados en suelos ricos, ayuda a que a pesar de la existencia de bacterias patógenas en el suelo, el animal no contraiga enfermedades, pues satisface sus necesidades nutricionales [15], [16]. En las haciendas evaluadas, se corroboró que la alimentación del ganado era una prioridad pues a pesar de que el estudio fue realizado en época de sequía, el ganado se encontraba en buenas condiciones de salud, debido a que la alimentación no variaba por épocas o por las reservas de forraje, además de complementar su dieta con balanceados y minerales.
Otro factor que afecta el crecimiento de Listeria es la competencia que se da con microorganismos propios de la leche y otros microorganismos patógenos, que hacen más difícil su supervivencia, debido a que deben competir por nutrientes con otras especies con un tiempo de duplicación más corto, como son las coliformes o las bacterias ácido lácticas, estas últimas se alimentan de lactosa provocando su rápido crecimiento y acidificando la leche rápidamente, lo que afecta el crecimiento de Listeria [17], [18], [11]. Además, se ha comprobado que estas bacterias tienen sustancias que inhiben la acción del patógeno, una de las sustancias es la bacteriocina que tiene acción bactericida sobre receptores específicos de las células y una capacidad de acción específica [18], [19].

También puede atribuirse al posible efecto inhibitorio de ácidos grasos propios de la leche, en [20], se determina, que los ácidos laúrico, linoléico y linolénico a $\mathrm{pH} 5 \pm 0.2$ son fuertemente bactericidas, provocando la ruptura de la membrana celular, así también, los ácidos grasos saturados pueden provocar lisis bacteriana por cambios en la fluidez de la membrana lipídica, provocando la muerte automática de la bacteria, esto se debe a que Listeria spp. tiene la capacidad de multiplicarse a valores de $\mathrm{pH}$ no menores a 4.4 lo que dificulta su crecimiento con bacterias ácido lácticas que soportan $\mathrm{pH}$ de 3.2 [18].

Según [16], cuando no se realizan prácticas adecuadas de limpieza en el ordeño, Listeria forma biopelículas sobre superficies inertes como en sistemas mecánicos de ordeño, tanques colectores y pezoneras que se utilizan para más de un animal, pues las vacas sanas se exponen a los organismos presentes en la leche proveniente de ubres de otras vacas infectadas [20]. En las tres haciendas evaluadas en este estudio se evidenció poca presencia de Listeria spp en muestras de leche, debido al uso de un sellador de pezones a base de yodo. Este elemento tiene características germicidas pues forma complejos surfactantes que eliminan a los patógenos causantes de mastitis, como Listeria monocytogenes [17] [21].

La higiene en el ordeño no solo se limita a los equipos sino también al animal. [19], menciona que las vacas con patas y ubres sucias, tienen mayor prevalencia de mastitis subclínica, que es la enfermedad más común que provoca Listeria monocytogenes en bovinos. En el 
Ecuador la norma INEN de la Higiene para la Leche y Productos Lácteos, obliga a todos los productores de leche a regirse a la limpieza de las ubres, tetillas, ingles y abdomen del animal para un ordeño en condiciones higiénicas; así también el lavado y desinfección adecuados de los tanques y pezoneras. Esto contribuyó a la poca presencia de Listeria spp. en esta investigación, pues las haciendas visitadas cumplían con la higiene básica para el ordeño [22].

En el análisis por PCR en Tiempo Real, se obtuvo un positivo en 60 muestras analizadas, lo que representa el $1.6 \%$ de presencia de Listeria spp en leche cruda. Estos resultados concuerdan con estudios previos de la presencia de esta bacteria en leche realizados en Irán, donde la prevalencia de Listeria en leche es de 7,3\%, es decir, 19 muestras infectadas de un total de 85, así también Moshtaghi y Mohamadpour citados en [14], demuestran que de 500 muestras, 11 de ellas presentaron Listeria que equivale al 2,2\%. En Sudamérica se han evidenciado estudios de presencia de Listeria spp. en leche cruda como en Colombia donde Rueda citado en [10], señala presencia del $22,2 \%$ y un $2 \%$ en leche pasteurizada. En este país la incidencia alcanza el 34\%. En Chile, Schöbitz y col citados en [10] mencionan que los análisis de leche cruda de 50 muestras arrojaron que la presencia de Listeria spp. es de $22 \%$, es decir, 11 muestras de las analizadas. Los estudios de Listeria spp. en leche cruda son limitados pero en derivados como el queso y yogurt se evindencia la presencia de la bacteria. Ramírez y col en [17] se refieren a queso blanco criollo, donde obtuvieron presencia en 8 de 30 muestras analizadas en Venezuela, así también en Argentina, Mengoni y Apraiz citados en [17], señalan que de 68 muestras de queso analizadas, en una se detectó presencia de Listeria y finalmente en Ecuador, existen escasos estudios sobre Listeria, sin embargo, Mena en [6], evalúa la prevalencia de la bateria en yogurt por medio de PCR en Tiempo Real y reporta que de 100 muestras, 4 resultaron positivas.

\section{Agradecimientos}

A MSc. Daniel Acurio por su colaboración en el análisis estadístico.

\section{Conclusiones}

La PCR en Tiempo Real permitió detectar concentraciones bajas de Listeria spp. en un período de tiempo corto en muestras de leche cruda, obteniendo un positivo en 60 muestras analizadas y 16 positivos de 45 muestras analizadas en quesos, lo que demuestra que esta técnica es adecuada para acortar el proceso de detección y obtener resultados verdaderos aún con poco material genético en las muestras.

Se determinó en la presente investigación que en la provincia de Pichincha, no existen cantidades representativas de Listeria spp. en leche cruda pero si existe una significancia estadística en quesos artesanales. Por las condiciones higiénicas, de suelo, alimentación y salud animal en las que se manejan las tres haciendas escogidas, el nivel de contaminación de leche cruda es bajo a pesar de estar poco tecnificadas y ser de baja producción, sin embargo, la escases de la bacteria no significa del todo seguridad microbiana en leche cruda, pues la bacteria puede convertirse en un problema alimentario grave en los productos procesados también.

\section{Referencias}

[1] "Producción lechera mueve \$ 700 millones al año", El Telégrafo, 2013. [En línea]. Disponible en: https://www. eltelegrafo.com.ec/noticias/economia/8/ produccion-lechera-mueve-700millones-al-ano [Accedido: 15-nov2016]

[2] R. A. Rojas y T. González, "Detección e identificación de bacterias causantes
Julio - Dic. 2017 ISSN 0122-820X E-ISSN 2422-5053 PP: 67-75 
No. 2

Julio - Dic. 2017

ISSN 0122-820X

E-ISSN 2422-5053

PP: 67-75 de enfermedades transmitidas por alimentos mediante la reacción en cadena de la polimerasa", Bioquimia, vol. 31, no. 2, pp. 69-76, 2006.

[3] L. A. Torres, "Prefactibilidad para la implementación de la producción y comercialización de leche cruda en la finca La Floresta", trabajo de fin de grado, Escuela Politécnica Nacional, Quito, Ecuador, 2009.

[4] L. Ramírez, A. Morón, A. Alfieri y O. Gamboa, "Detección de Listeria monocytogenes en queso blanco criollo, mediante la reacción en cadena de la polimerasa (PCR)", Archivos Latinoamericanos de Nutrición, vol. 60, no. 3, pp. 254-260, 2010.

[5] P.A. Mera, "Evaluación de la calidad de leche mediante citometría de flujo, proveniente de bovinos de la Parroquia Machachi, Provincia de Pichincha", trabajo de fin de grado, Universidad de las Fuerzas Armadas ESPE, Sangolquí, Ecuador, 2013.

[6] M.C. Mena, "Evaluación de la prevalencia de Listeria monocytogenes en productos lácteos y embutidos en tres mercados de la ciudad de Quito mediante la técnica de la reacción en cadena de la polimerasa en tiempo real", trabajo de fin de grado, Pontificia Universidad Católica del Ecuador, Quito, Ecuador, 2010.
[7] B. Sánchez y E. Palencia, "Infecciones por Listeria", Medicine (Baltimore), vol. 10, no. 50, pp. 3368-3372, 2010.

[8] F.E. Acevedo, L. Navarro-Escalante, L. M. Constantino, Z. Gil y P. Benavides, "Método rápido y económico para la extracción de ADN genómico en la broca del café y su uso en pcr", Cenicafé, vol. 58, no. 2, pp. 134-141, 2007.
[9] G. Amagliani, C. Giammarini, E. Omiccioli, G. Brandi and M. Magnani, "Detection of Listeria monocytogenes using a commercial PCR kit and different DNA extraction methods", Food Control, vol. 18, no. 9, pp. 11371142, 2007.

[10] V. Chiluisa y A. Echeverría, "Identificación y cuantificación de Salmonella sp. y ADNr 16S bacteriano mediante PCR en tiempo real en muestras de alimentos", Bionatura, vol. 2, no. 1, pp. 241-244, 2017.

[11] R. Schobitz, M. Marín, M. Horzella y E. Carrasco, "Presencia de listeria monocytogenes en leche cruda y quesos frescos artesanales", Agro Sur, vol. 29, no. 2, pp. 114-119, 2001.

[12] R. Pagano, Estadística para las ciencias del comportamiento. México, D.F.: Cengafe learning, 2011.

[13] P. Yáñez, "Biometría y Bioestadística Fundamentales", Autopublicación, vol 15, no. 3, pp.43-45, 2010.

[14] E. Rahimi, H. Momtaz, A. Behzadnia and Z.T. Baghbadorani, "Incidence of Listeria species in bovine, ovine, caprine, camel and water buffalo milk using cultural method and the PCR assay", Asian Pacific Journal of Tropical Disease, vol. 4, no. 1, pp. 50-53, 2014.

[15] F. Alba, Pastos y Forrajes. Instituto Técnico Superior Agronómico Salesiano, 2012.

[16] H.P. McLaughlin, P.G. Casey, J. Cotter, C.G. Gahan and C. Hill, "Factors affecting survival of Listeria monocytogenes and Listeria innocua in soil samples", Archives of Microbiology, vol. 193, no. 11, pp. 775-785, 2011.

[17] A. Carrascal, Y. Albarracín y P. 
Sarmiento, "Incidencia de listeria monocytogenes en leche de vaca expendida en el municipio de Pamplona, Colombia", Bistua: Revista de la

Facultad de Ciencias Básicas, vol. 5, no. 2, pp. 49-57, 2007.

[18] J.C. Ramírez, P.R. Ulloa, M. Yanira, J.A. Ulloa y F. Arce, "Bacterias lácticas: Importancia en alimentos y sus efectos en la salud", Revista Fuente, vol. 2, no. 7, 2011.

[19] H. Suárez, A. De Francisco y L. Beirao, "Influencia de las bacteriocinas producidas por Lactobacillus plantarum LPBM10 sobre la vida útil de filetes del híbrido de cachama Piaractus brachypomus x Colossoma macropomum empacado al vacío", Vitae, Resvista de la Facultad de Quimica Farmaceutica, vol. 15, no. 1, 2008.

[20] P. Ruegg, "Manejo Hacia la Calidad de la Leche", 2004. [En línea] Available: http://milkquality.wisc.edu/wp-content/ uploads/2011/09/managing-formilkquality_spanish.pdf [Accedido: 12dic-2016]

[21] J. Vera, "Identificación y evaluación de los factores que influyen en la calidad de leche de las fincas proveedoras de la fábrica de quesos la Holandesa", trabajo de fin de grado, Escuela Politécnica Del Ejército, Quito, Ecuador, 2005.

[22] J. Gallegos et al., "Frecuencia de Listeria sp., en quesos Colombianos Costeños", Revista MVZ Córdoba, vol. 12, no. 2, pp. 996-1012, 2007. 